\title{
Swimming and feeding in Periphylla periphylla (Scyphozoa, Coronatae)
}

\author{
Tom A. Sørnes · Aino Hosia • Ulf Båmstedt • \\ Dag L. Aksnes
}

Received: 11 May 2006/Accepted: 1 October 2007/Published online: 30 October 2007

(C) Springer-Verlag 2007

\begin{abstract}
Some western Norwegian fjords host extraordinarily abundant and persistent populations of the mesopelagic, coronate scyphomedusa, Periphylla periphylla. In these environments, from late autumn to spring, the medusae undertake regular diel vertical migrations into surface waters. From unique observations obtained with a remotely operated vehicle (ROV), including observations made without artificial light, we observed that $90 \%$ of the medusae swam with their tentacles in aboral position. Stomach content analyses of surface-collected specimens revealed that the medusae ate mainly calanoid copepods, but ostracods and large euphausiids were also prominent components of their diets. The clearance rate potential of $P$. periphylla, assessed from in situ observations and stomach contents, was comparable to that of similar-sized, epipelagic gelatinous species. Our findings suggest that $P$. periphylla behave as active predators in surface waters.
\end{abstract}

\section{Introduction}

Planktonic cnidarians comprise a heterogeneous group in terms of functional morphology, swimming and foraging

Communicated by M. Kühl.

T. A. Sørnes $(\bowtie) \cdot$ A. Hosia · U. Båmstedt · D. L. Aksnes Department of Biology, University of Bergen,

PO Box 7800, 5020 Bergen, Norway

e-mail: tosorn@statoilhydro.com

U. Båmstedt

Umeå Marine Science Centre,

Norrbyn, 91020 Hörnefors, Sweden patterns. The various mechanisms involved in prey encounter and capture processes can lead to interspecific dietary differences (Costello and Colin 2002). Our current knowledge of these mechanisms is fragmentary. As a consequence, so is our understanding of the prey selection patterns and trophic impacts of cnidarians. Based on their prey encounter tactics, gelatinous planktivores have been classified as either ambushing or cruising entangling predators (Greene 1985). Ambushing predators remain stationary, waiting for prey to contact them, and only move to reposition. Cruising predators are in constant motion and swimming and prey capture are simultaneous, interrelated processes (Madin 1988). Recent studies have proposed that predation mode is connected to bell morphology for some shallow-water hydromedusae and scyphomedusae (Ford et al. 1997; Colin and Costello 2002; Colin et al. 2003), ambushers being characterized by streamlined bells and cruisers by flat bells. However, alternative foraging strategies seem to exist (Raskoff 2002), suggesting that a refinement of the above classification scheme is needed.

Our understanding of the abundance, distribution and natural behaviours of meso- and bathypelagic gelatinous zooplankton is in its infancy (Dennis 2003). Traditional approaches, such as sampling with plankton nets, tend to damage their delicate bodies (Dennis 2003; Haddock 2004). The creatures from this deep, dim realm may be sensitive to the changes in light, pressure and temperature often associated with bringing live samples to the surface. And so, retrieving specimens in pristine condition for shipboard and laboratory experiments remains immensely challenging. The introduction of research submarines has permitted detailed explorations of deep-sea animals in their natural habitats (Haddock 2004; Robison 2004). In situ observations and experimentation at great depth have become 
realistic, albeit expensive, alternatives to laboratory studies (NRC 2003). Several challenges, such as controlling variables and replicating observations (Madin 1988), may nonetheless pertain to in situ operations. Semi-enclosed habitats, like fjords, provide ideal environments to study midwater residents, such as some gelatinous zooplankton. Water exchange is generally restricted, especially in fjord basins, and the animal communities therein remain resident for prolonged periods. The inherently calm sea state in fjords permits continuous operations, virtually undisturbed by rough weather.

Dense populations of the perennial, midwater coronate scyphomedusa Periphylla periphylla have been reported for several western Norwegian fjords (Fosså 1992; Youngbluth and Båmstedt 2001). In Lurefjorden, P. periphylla is an apex predator, with no obvious competitors or predators (Youngbluth and Båmstedt 2001). The majority of the population undertakes diel vertical migrations, with distances ranging from 100 to $400 \mathrm{~m}$, and nocturnal surface swarming has been occasionally observed from late autumn to spring (Youngbluth and Båmstedt 2001). Preliminary observations have indicated that $P$. periphylla drift with their tentacles first or laterally extended. The former posture was recently described for the midwater narcomedusae Solmissus spp. and termed "ramming" (Raskoff 2002). Ramming involves approaching your prey tentacles-first, to avoid the fluid disturbance associated with swimming-induced escape responses.

Ramming may be a common foraging strategy for midwater medusae, but our knowledge on the diets and predation potentials of "rammers" is scarce (Raskoff 2002). We obtained video recordings of $P$. periphylla, using a remotely operated vehicle (ROV), as the population surfaced in Lurefjorden, April 2004. We also assessed the abundance and distribution of the medusae and their mesozooplankton prey, and obtained stomach contents from surface-collected specimens. Their potential clearance rates were quantified using both field observations and stomach contents.

\section{Materials and methods}

\section{Study site}

Sampling and all observations were made from 20 to 26 April 2004 in Lurefjorden, western Norway. The fjord is $22 \mathrm{~km}$ long and its maximum depth is $439 \mathrm{~m}$. Water exchange is mainly driven by tidal currents and local weather conditions (Youngbluth and Båmstedt 2001). Vertical profiles of salinity, temperature and dissolved oxygen were obtained using a Seabird 911 CTD (Sea-Bird Electronics, Washington, USA).
P. periphylla: behaviour and swimming performance

The behaviour of $P$. periphylla was observed in situ using the ROV Aglantha. The vehicle was equipped with a Sony EVI-401 colour-camera, and the observations were recorded on SVHS and DVCam tapes for later analysis. During the study period, we made four dives videotaping medusae at 15-40 $\mathrm{m}$ depth. The dives took place at dusk and dawn, when large specimens ( $>5 \mathrm{~cm}$ in coronal diameter) appeared close to the surface. On two of the dives, from hereon referred to as "behavioural dives", we tracked single medusae $(\sim 3-8 \mathrm{~min}$ per medusa, $n=15)$ using exclusively red illumination $(>660 \mathrm{~nm})$. On the two remaining dives, Aglantha maintained a fixed position at a depth of $25-30 \mathrm{~m}$. The lights were switched off, the camera tilted upwards and $P$. periphylla videotaped as they swam by the camera at a distance. Using this setup, lighting and mechanical disturbance from the vehicle were unlikely to affect medusan behaviour, but the observation period was reduced to $15-155 \mathrm{~s}$ per medusa $(n=102)$. The natural sunlight and moonlight proved sufficient to observe both bell contraction rates $\left(\mathrm{s}^{-1}\right)$ and tentacle postures. For the medusae videotaped under red illumination, we also noted whenever a tentacle was inserted into the gastric cavity (apparent feeding bout) and the total time that each tentacle was concealed (apparent handling time, s). These observations were used to estimate clearance rates of the medusae (see below). Unfortunately, the video records lacked sufficient resolution to identify prey attached to the tentacles.

P. periphylla: vertical distributions, stomach contents and prey abundance

The vertical distributions of $P$. periphylla were determined using Aglantha ( $n=4$ dives). We profiled the whole water column before and after the "behavioural dives" and noted the depth of each medusa. The descent rate of the vehicle was $<0.5 \mathrm{~m} \mathrm{~s}^{-1}$. Four $500 \mathrm{~W}$ halogen lights and four $150 \mathrm{~W}$ high intensity discharge (HID) gasarc lights illuminated the field of view. From these profiles, we assessed to what extent the medusae overlapped with their mesozooplankton prey. P. periphylla $(n=70)$ were also collected from the surface waters at night, over the entire 7-day period, using 3-10 1 containers. Their stomachs were opened and the contents immediately examined at $10-50 \times$ magnification with a light microscope.

To determine the abundance and vertical distribution of mesozooplankton, Multinet samples $\left(0.25 \mathrm{~m}^{2}\right.$ mouth area, $180 \mu \mathrm{m}$ mesh, Hydrobios Company, $n=2$ hauls) were collected from bottom to surface after the 
"behavioural dives". The five nets were opened and closed to cover the intervals 400-300, 300-200, 200-100, 100-50 and 50-0 $\mathrm{m}$ depth, respectively. The samples were immediately preserved in 5\% buffered formalin and returned to the laboratory for species identification and enumeration.

P. periphylla: encounter zone volumes and tentacle densities

The encounter radii of gelatinous tentaculate predators are determined by the arrangement and dimensions of tentacles and their swimming behaviours. In constructing a conceptual encounter model for gelatinous predators, Madin (1988) introduced the two spatial parameters "encounter zone" and "tentacle density". He defined the encounter zone as "the space into which tentacles can extend when the predator is fishing" and tentacle density as "the fraction of the encounter zone filled with tentacles". We expressed these two parameters for $P$. periphylla, based on the observed behaviour and tentacle postures, to facilitate comparison with other functional types of medusae (Madin 1988).

Swimming tentacles-first was characteristic of $P$. periphylla (see "Results"). The 12 tentacles defined the boundaries of the medusa's encounter zone, as approximated by a truncated cone (Fig. 1). The volume covered by this zone can be expressed as (modified after Madin 1988):

$V_{C}=\frac{\pi}{3} H\left(r_{1}^{2}+r_{2}^{2}+r_{1} r_{2}\right)-\frac{\pi}{3} r_{1}^{2} h$

where $V_{C}$ is encounter zone volume $\left(\mathrm{m}^{3}\right), H$ is truncated cone height $(\mathrm{m}), r_{1}$ is coronal radius $(\mathrm{m}), r_{2}$ is cone radius $(\mathrm{m})$ and $h$ is dome height $(\mathrm{m})$. The subtracted term represents the volume covered by the dome (see Fig. 1 for further details). The coronal diameter, cone diameter (distance between two opposite tentacle tips), dome height, and tentacle length (used below) were estimated in situ using the paired-beam laser mounted on Aglantha.

Once inside the encounter zone, the likelihood that prey collide with tentacles is influenced by tentacle density $\left(D_{t}\right)$, defined as total tentacle volume $\left(V_{\mathrm{t}}\right)$ divided by encounter zone volume ( $V_{C}$, Madin 1988):

$D_{\mathrm{t}}=\frac{12 r_{3}^{2} L}{H\left(r_{1}^{2}+r_{2}^{2}+r_{1} r_{2}\right)-r_{1}^{2} h}$

where $D_{\mathrm{t}}$ is tentacle density, $r_{3}$ is tentacle radius $(\mathrm{m})$ and $L$ is tentacle length $(\mathrm{m})$. The volume of each tentacle was approximated by a cone $\left(\frac{\pi}{3} r_{3}^{2} L\right)$. We assumed a baseline tentacle diameter of $0.5 \mathrm{~cm}$ in the calculations.

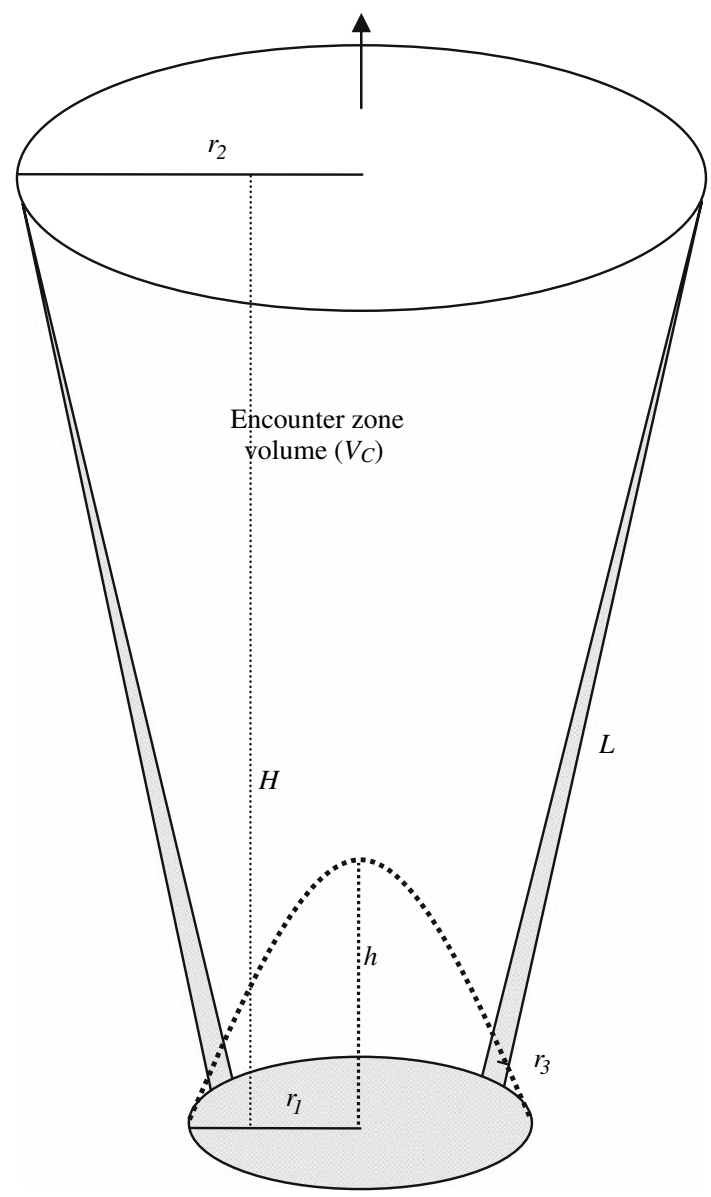

Fig. 1 Periphylla periphylla. A schematic drawing of the encounter zone volume $\left(V_{C}\right)$, with boundaries defined by the tentacles (only two shown). The dotted line indicates the dome. $H$ is cone height, $h$ is dome height, $L$ is tentacle length, $r_{1}$ is coronal radius, $r_{2}$ is cone radius and $r_{3}$ is tentacle radius. Swimming direction is indicated by the arrow. See "Materials and methods" for further details

\section{P. periphylla: clearance rate estimates}

We estimated clearance rates from the in situ observations of feeding bouts $\left(a_{1}\right)$ and the stomach contents of surfacecollected medusae $\left(a_{2}\right)$ :

$a_{1}=\frac{F}{N}$

$a_{2}=\frac{C}{T N}$

where $a_{1}$ and $a_{2}$ are predicted clearance rates $\left(\mathrm{m}^{3} \mathrm{~s}^{-1}\right), F$ is number of apparent feeding bouts per time, $N$ is prey density (individuals $\mathrm{m}^{-3}$ ), $C$ is stomach content (the number of copepod prey per medusa) and $T$ is digestion time (s). Digestion times for $P$. periphylla were unavailable. Since digestion times for pelagic cnidarians feeding on small crustaceans normally span from $2-4 \mathrm{~h}$ over a broad temperature range (Purcell 1997), we used $4 \mathrm{~h}$ as a 
conservative estimate in our calculations. However, we recognize that the digestion times for large Calanus species and euphausiids may be even longer.

\section{P. periphylla: fluid flow}

The fluid flow around swimming P. periphylla was visualized using sepia ink. Medium-sized specimens (4-5 cm in coronal diameter, $n=5$ ) were dipped from the surface waters at night and brought back to the onshore laboratory in 51 dark chambers. The medusae were placed in a planktonkreisel $(73 \mathrm{~cm}$ in diameter, $15 \mathrm{~cm}$ in width) with continuous flow and kept in a dark and temperature-controlled $\left(10^{\circ} \mathrm{C}\right)$ room. Single medusae were then transferred to an experimental tank $(34 \times 34 \times 59 \mathrm{~cm})$ for shorter time periods. Here, the ink was introduced ahead of the swimming medusae, which were then videotaped (Sony CCD AVC-D5CE, Olympus Sigma Mini-Wide lens) as they swam through it. All sequences were filmed under red illumination. Attempts were made to use particles as current tracers instead of sepia ink. However, their contrast against the dim (red) background was insufficient to support further analyses. This prevented a more thorough investigation of the important flow characteristics around swimming $P$. periphylla.

\section{Results}

\section{Hydrography}

The water column was virtually isothermal $\left(6.0-6.8^{\circ} \mathrm{C}\right)$ and isohaline (31.9-33.1 ppt) at the sampling station. From saturation in surface waters, the oxygen content decreased to $2.9 \mathrm{ml} \mathrm{l}^{-1}$ near the bottom, well above hypoxic levels (Diaz and Rosenberg 1995).

\section{P. periphylla: behaviour and swimming performance}

There was no significant difference $(t$ test, $P>0.05, d f=$ $115)$ in pulsation frequency between medusae viewed under red illumination $\left(11.8 \pm 2.6\right.$ contractions $\mathrm{min}^{-1}$, mean $\pm \mathrm{SD}, n=15)$ and natural illumination (13.0 \pm 3.2 contractions $\min ^{-1}$, mean $\pm \mathrm{SD}, n=102$ ). We also did not observe changes in swimming direction or tentacle deployment patterns, suggesting that the medusae were unaffected by the red light.

Two basic swimming postures were observed in situ, regardless of the spatial orientation of $P$. periphylla. The tentacles-first posture, where the tentacles were held in aboral position, almost parallel to the swimming axis

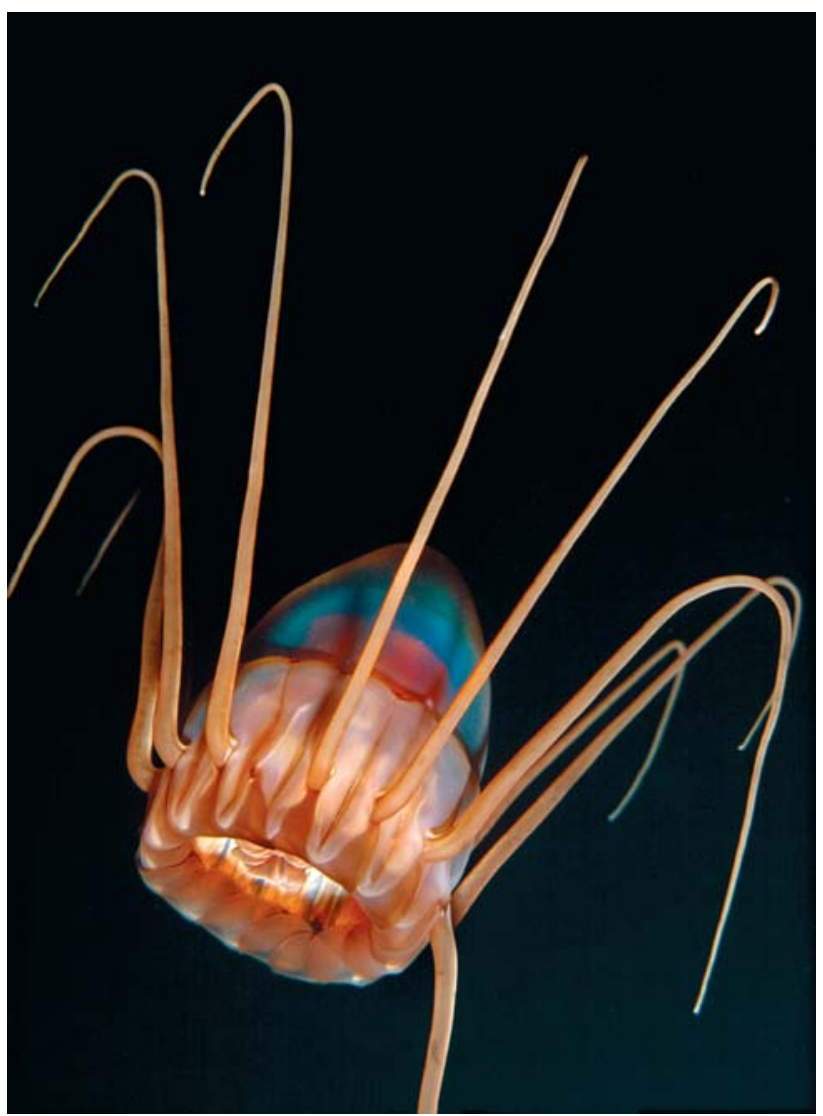

Fig. 2 The dominant tentacle posture of $P$. periphylla observed in shallow waters. Photo courtesy of Erling Svendsen

(45-90 ${ }^{\circ}$ off the plane of the umbrella), dominated $(89.7 \%$, total $n=117$, Fig. 2). The tentacle tips were often slightly bent. In the less dominant posture $(7.7 \%)$, the tentacles were perpendicular to the swimming axis $\left(0-45^{\circ}\right.$ off the plane of the umbrella). The remaining $2.6 \%$ of the medusae were observed showing a combination of postures, with tentacles oriented in different directions. Medusae were found in all orientations and continuously swimming (percent time swimming $=100$ ).

Eleven out of the 15 medusae observed under red illumination were apparently feeding when swimming with their tentacles first. Whenever a tentacle arched away from the dome and approached the mouth, the distal part coiled. The coiled portion was inserted into the mouth and concealed in the gastric cavity. This concealment lasted for $52.0 \pm 17.8 \mathrm{~s}$ (mean $\pm \mathrm{SD}, n=15$ ).

P. periphylla: vertical distributions, prey abundance and stomach contents

The vertical distributions of $P$. periphylla at daytime and dusk (Fig. 3a) suggested pronounced diel vertical 
Fig. 3 The vertical distributions of $P$. periphylla (a, left panel) and copepods (dark grey bars) and ostracods (light grey bars, $\mathbf{b}$, right panel) in Lurefjorden, April 2004. The dives are representative examples of day and dusk distributions. The conversion from counts (number of medusae per depth interval) to densities (number of medusae per $100 \mathrm{~m}^{-3}$ ) was done according to the transformation factors in Youngbluth and Båmstedt (2001)

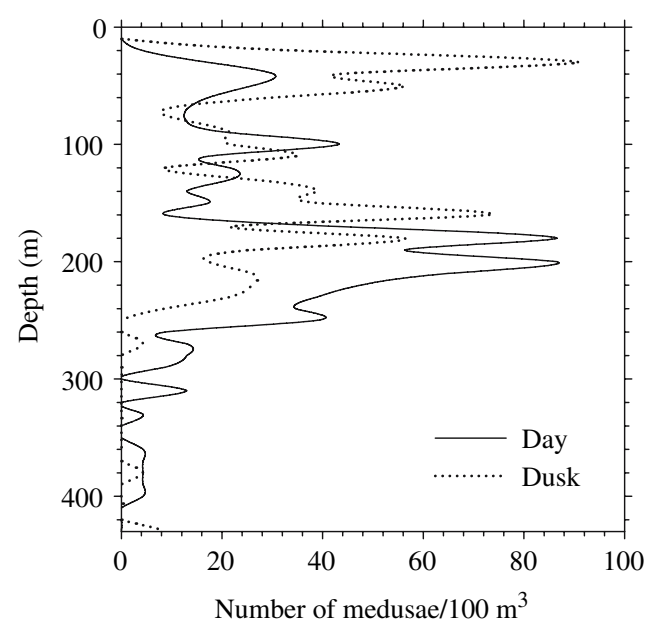

migrations. The distribution at dusk was bimodal, and the upper mode overlapped with the surface peak of copepods (Fig. 3b), numerically dominated $(83 \%)$ by Calanus spp. of stages III-V. Together with Microcalanus sp., Pseudocalanus sp. and Oithona sp., it constituted more than $98 \%$ of the copepod community. The peak of copepods between 300 and $400 \mathrm{~m}$ was numerically dominated $(96 \%)$ by the much smaller Microcalanus sp. Ostracods were common throughout the water column, but most abundant between 50 and $100 \mathrm{~m}$ (Fig. 3b). In the calculations of clearance rates, we used the mean copepod density between surface and $50 \mathrm{~m}$ depth, 425 individuals $\mathrm{m}^{-3}$. The copepods did not conduct diel vertical migrations during the study period (Riemann et al., unpublished data).

The main prey items found in the stomachs of $P$. periphylla were calanoid copepods, especially Calanus spp. $92.9 \%$ of the medusae contained copepods (range 1-131 copepods per medusa, mean $\pm \mathrm{SD}=23.7 \pm 29.8), 15.7 \%$ contained exoskeletons of the northern krill Meganyctiphanes norvegica (range 1-3 krill per medusa, mean $\pm \mathrm{SD}=1.3 \pm 0.7$ ) and $8.6 \%$ contained the ostracod Conchoecia spp. (range 2-13 ostracods per medusa, mean $\pm \mathrm{SD}=4.5 \pm 4.2$ ). The dissected medusae had a mean coronal diameter of $7.5 \pm 1.7 \mathrm{~cm}$ (mean $\pm \mathrm{SD}$, $n=70$ ). A total of $24 \%$ of the copepods (total $n=1,538$ ) were partly digested and not identifiable to the genus, which prevented calculations of electivity indices.

\section{$P$. periphylla: encounter zone volumes, tentacle densities and clearance rates}

The mean encounter zone volumes and tentacle densities were $6.9 \pm 3.9 \times 10^{-3} \mathrm{~m}^{3}$ and $3,564 \pm 1,782 \mathrm{ppm}$, respectively (mean $\pm \mathrm{SD}, n=15$ ). From the in situ observations of apparent feeding bouts we estimated a mean clearance rate $\left(a_{1}\right)$ of $0.76 \pm 0.16 \mathrm{~m}^{3}$ day $^{-1}$ (mean $\pm \mathrm{SD}, n=15$ ). This estimate was somewhat higher than that based on the stomach contents of copepods $\left(a_{2}=0.31 \pm 0.43 \times 10^{-6} \mathrm{~m}^{3} \mathrm{~s}^{-1}\right.$, mean $\left.\pm \mathrm{SD}, n=70\right)$. However, the clearance rate estimates based on in situ observations assume $100 \%$ retention efficiencies, and are therefore likely to be overestimates of true clearance rates.

\section{P. periphylla: fluid flow}

$P$. periphylla swam tentacles-first in the experimental tank. The flow appeared to be laminar passing through the tentacles, and toroids were first observed when the ink approached the marginal lappets. The wake seemed more consistent with jet propulsion than a rowing kind of thrust production. However, these analyses are preliminary, and more rigorous studies are encouraged to reveal the detailed flow patterns around these medusae.

\section{Discussion}

The prey encounters of ambush predators are exclusively determined by tentacle dimensions and postures, prey size and motility. Prolate bells experience less drag than oblate bells (Colin et al. 2003), and minimizing the area of the velar opening through which water exits the subumbrellar cavity increases the velocity and momentum flux of the expelled fluid (Colin and Costello 2002). This facilitates rapid repositioning, whereafter the medusae can resume their drift posture. Based exclusively on their prolate shape, $P$. periphylla would be expected to behave as ambushers. However, the medusae observed in this study were constantly swimming. Cruisers generally have a rowing propulsive mode. Their swimming enhances the water flow past tentacles and other primary capture surfaces (Costello 1992), thus facilitating prey encounter. Stealth predation or 
"ramming" may be considered as an intermediate strategy. Swimming and feeding are interrelated, unlike for "pure" ambush predators. However, the swimming-generated fluid disturbance seems decoupled from prey encounters (Raskoff 2002), unlike for cruising predators.

$P$. periphylla were most often observed swimming, and feeding, with their tentacles in aboral position, suggesting that they behaved as "ramming" stealth predators. Similar tentacle postures have been described for other coronate scyphomedusae (Larson 1979), some narcomedusae (Madin 1988; Mills and Goy 1988; Larson et al. 1989; Raskoff 2002) and limnomedusae (Raskoff 2002). Fewer specimens were observed swimming with their tentacles laterally extended. One would expect the fluid deformations generated by swimming medusae to be readily perceived by both copepods and euphausiids and elicit pre-encounter escape responses. However, if the swimming-generated fluid disturbance for $P$. periphylla was decoupled from their encounter zone, as described for other "rammers" (Raskoff 2002), this could enable them to approach highly motile (and sensitive) prey without causing escape responses. The presence of large euphausiids in the stomachs of surface-collected medusae, as well as the "tank observations" of main flow patterns support this notion.

Compared with the species/genera of medusae listed in Madin (1988), and regardless of the encounter zone shape and size, $P$. periphylla have high tentacle densities. For a given tentacle posture, $P$. periphylla can increase the volume searched for prey by (1) increasing the dimension and/or number of tentacles, or (2) increasing the swimming speed. Both infer energetic costs that have to be compensated. We would expect medusae not behaving as "rammers" to increase their cone radius $\left(r_{2}\right)$, thereby exposing more of the tentacle surface in the direction of movement. And indeed, the less dominant posture $(7.7 \%)$ observed in this study was laterally extended tentacles, which corresponds to maximizing the projected surface area.

The coronate tentacle has a tube-within-a-tube arrangement and root-like extensions into the umbrellar mesoglea, providing strength and rigidity (Larson 1979). This enables $P$. periphylla to retain its tentacles in upright position during forward motion. The tentacles were often arched outwards with bent tips. This was most probably a function of tentacle length (Larson et al. 1989), as the tentacles tapered with increasing distance from the bell, reducing their ability to withstand drag. The 12 tentacles were widely spaced, an arrangement seemingly not well suited for capturing small prey items (Madin 1988; Purcell and Mills 1988).

Both the strong tentacles and giant nematocysts of $P$. periphylla may be a specialization for capturing large and motile prey. Their cnidome consists of holotrichous isorhizas and heterotrichous microbasic euryteles, typical for all coronates (Jarms et al. 2002). The tentacles are lined with euryteles, thought to be responsible for penetrating and holding on to prey. Their giant euryteles are the largest described for any scyphozoan (Jarms et al. 2002). Keeping their tentacles in the mouth for a prolonged period following capture (=long handling time) may decrease the chances of prey escaping from the gut.

Approximately $97 \%$ of the surface-collected $P$. periphylla contained prey. Whether the dominance of calanoid copepods in their stomachs reflected active selection, or merely the predominance of these prey in the plankton, remains uncertain. Both crustaceans and decapods, and midwater fishes have been reported in the stomachs of P. periphylla sampled with plankton nets (Maas 1897; Larson 1979). However, Youngbluth and Båmstedt (2001) suspected that the medusae ingested extraneous prey in the cod-end bags, lending little support to the above records. Other ramming medusae eat mainly large, gelatinous prey (Mills and Goy 1988; Larson et al. 1989; Mills et al. 1996; Raskoff 2002). Apart from P. periphylla, cnidarians and ctenophores are virtually absent in Lurefjorden (Youngbluth and Båmstedt 2001), but whether this is due to predation by $P$. periphylla is not known. The digestion of potential gelatinous prey would be rapid, making detection from gut contents difficult (e.g., Arai 2005).

The $P$. periphylla we examined contained much higher numbers of prey than previously reported. In March 1992, Fosså (1992) dissected 39 surface-collected $P$. periphylla from Lurefjorden. Only 24 of the medusae contained a total of 39 preys. The preys were identified as Calanus finmarchicus and Euchaeta norvegica in a 2:1 ratio, as well as remnants of a natant decapod. In August and December 1999, Youngbluth and Båmstedt (2001) collected 41 medusae from Lurefjorden with ROV samplers. Only $10 \%$ contained prey, and in small numbers (1-3 copepods or a single chaetognath and 2-4 ostracods per medusa). Since there was no information on prey densities (Fosså 1992) or depth of capture (Youngbluth and Båmstedt 2001) in these studies, clearance rates for comparison could not be calculated. Our clearance rate estimates for $P$. periphylla (3.6 and $8.8 \times 10^{-6} \mathrm{~m}^{3} \mathrm{~s}^{-1}$ ) are consistent with published records from similar-sized gelatinous zooplanktivores feeding on small crustaceans (Sørnes and Aksnes 2004).

Meganyctiphanes norvegica can be important food items for P. periphylla in Lurefjorden. The basal metabolic requirements of medium-sized $(1.5-7.5 \mathrm{~cm}$ in coronal diameter) $P$. periphylla are equivalent to $0.2-8 \mathrm{mg}$ Carbon day ${ }^{-1}$ (Youngbluth and Båmstedt 2001). M. norvegica from Skagerrak waters and the Norwegian northwest coast range from 30-80 mg Dry Weight individual ${ }^{-1}$ (Båmstedt and Karlson 1998). Assuming a mean carbon content of $40.2 \%$ of DW (Lindley et al. 1999), each euphausiid 
contains $12-32 \mathrm{mg} \mathrm{C}$. Based on carbon requirements, one $M$. norvegica would therefore meet the daily metabolic needs of medium-sized $P$. periphylla. It would take 1-34 (7.8 \pm 0.6 , mean \pm SD, Youngbluth and Båmstedt 2001) Calanus spp. to meet the same demands.

Surface swarming by medusae normally inhabiting the midwater realm is rare. The unique setting in this study allowed detailed observations of the swimming behaviours and tentacle postures adopted by $P$. periphylla. Our findings suggest that the medusae behave as active "rammers" in the epipelagic, and not passive drifters as previously assumed. Because $P$. periphylla are notoriously difficult to keep in captivity (Youngbluth and Båmstedt 2001, personal observations), field studies may be the easiest, and perhaps the only, way to explore their feeding ecology.

Acknowledgments This investigation was supported by EUROGEL (EUROpean GELatinous Zooplankton, European Commission Contract no. EVK-CT-2002-00074), the Research Council of Norway (project no. 146994/120), the Meltzer Foundation and the Finnish Cultural Foundation. The assistance of collaborating scientists and the crew of R/V Håkon Mosby are greatly appreciated.

\section{References}

Arai MN (2005) Predation on pelagic coelenterates: a review. J Mar Biol Assoc UK 85:523-536

Båmstedt U, Karlson K (1998) Euphausiid predation on copepods in coastal waters of the Northeast Atlantic. Mar Ecol Prog Ser 172:149-168

Colin SP, Costello JH (2002) Morphology, swimming performance and propulsive mode of six co-occurring hydromedusae. J Exp Biol 205:427-437

Colin SP, Costello JH, Klos E (2003) In situ swimming and feeding behaviour of eight co-occurring hydromedusae. Mar Ecol Prog Ser 253:305-309

Costello JH (1992) Foraging mode and energetics of hydrozoan medusae. Sci Mar 56:185-191

Costello JH, Colin SP (2002) Prey resource use by coexistent hydromedusae from Friday Harbor, Washington. Limnol Oceanogr 47:934-942

Dennis C (2003) Close encounters of the jelly kind. Nature 426:12-14

Diaz RJ, Rosenberg R (1995) Marine benthic hypoxia: a review of its ecological effects and the behavioural responses of benthic macrofauna. Oceanogr Mar Biol 33:245-303

Ford MD, Costello JH, Heidelberg KB, Purcell JE (1997) Swimming and feeding by the scyphomedusa Chrysaora quinquecirrha. Mar Biol 129:355-362
Fosså JH (1992) Mass occurrence of Periphylla periphylla (Scyphozoa, Coronatae) in a Norwegian fjord. Sarsia 77:237-251

Greene CH (1985) Planktivore functional-groups and patterns of prey selection in pelagic communities. J Plankton Res 7:35-40

Haddock SHD (2004) A golden age of gelata: past and future research on planktonic ctenophores and cnidarians. Hydrobiologia 530/ 531:549-556

Jarms G, Tiemann H, Båmstedt U (2002) Development and biology of Periphylla periphylla (Scyphozoa: Coronatae) in a Norwegian fjord. Mar Biol 141:647-657

Larson RJ (1979) Feeding in coronate medusae (Class Scyphozoa, Order Coronatae). Mar Behav Physiol 6:123-129

Larson RJ, Mills CE, Harbison GR (1989) In situ foraging and feeding behaviour of narcomedusae (Cnidaria, Hydrozoa). J Mar Biol Assoc UK 69:785-794

Lindley JA, Robins DB, Williams R (1999) Dry weight, carbon and nitrogen content of some euphausiids from the North Atlantic Ocean and the Celtic Sea. J Plankton Res 21:2053-2066

Maas O (1897) Reports on an exploration off the west coasts of Mexico, Central and South America, and off the Galapagos Islands. XXXI Die Medusen. Mem Mus Comp Zool Harv 23:992

Madin LP (1988) Feeding behaviour of tentaculate predators: in situ observations and a conceptual model. Bull Mar Sci 43:413-429

Mills CE, Goy J (1988) In situ observations of the behaviour of mesopelagic Solmissus narcomedusae (Cnidaria, Hydrozoa). Bull Mar Sci 43:739-751

Mills CE, Pugh PR, Harbison GR, Haddock SHD (1996) Medusae, siphonophores and ctenophores of the Alboran Sea, south western Mediterranean. Sci Mar 60:145-163

National Research Council (2003) Future needs in deep submergence science: occupied and unoccupied vehicles in basic ocean research. The National Academies Press, Washington DC

Purcell JE (1997) Pelagic cnidarians and ctenophores as predators: Selective predation, feeding rates, and effects on prey populations. Ann Inst Oceanogr Paris 73:125-137

Purcell JE, Mills CE (1988) The correlation between nematocyst types and diets in pelagic Hydrozoa. In: Hessinger DA, Lenhoff HM (eds) The biology of nematocysts. Academic, Orlando, pp 463-485

Raskoff KA (2002) Foraging, prey capture, and gut contents of the mesopelagic narcomedusa Solmissus spp. (Cnidaria: Hydrozoa). Mar Biol 141:1099-1107

Robison BH (2004) Deep pelagic biology. J Exp Mar Biol Ecol 300:253-272

Sørnes TA, Aksnes DL (2004) Predation efficiency in visual and tactile zooplanktivores. Limnol Oceanogr 49:69-75

Youngbluth MJ, Båmstedt U (2001) Distribution, abundance, behaviour and metabolism of Periphylla periphylla, a mesopelagic coronate medusa in a Norwegian fjord. Hydrobiologia 451:321333 